\title{
scripted
}

Volume 16, Issue 1, August 2019

\section{Anniversary conference report}

\author{
Giorgos D. Vrakas* and Thomas Broderick**
}

\section{(c) (1) $\odot \odot$}

(C) 2019 Giorgos D. Vrakas and Thomas Broderick Licensed under a Creative Commons Attribution-NonCommercial-

NoDerivatives 4.0 International (CC BY-NC-ND 4.0) license

DOI: 10.2966/scrip.160119.69

\footnotetext{
* Editor-In-Chief, SCRIPTed, Giorgos.Vrakas@ed.ac.uk

** Managing Editor, SCRIPTed, Thomas.Broderick@ed.ac.uk
} 
The conference began with an introduction by the editor in chief (Giorgos D. Vrakas) welcoming everyone to the conference and outlining the format of the day's talks i.e. 30 minutes per speaker with a 15-minute question and answer session at the end, followed by a round table open discussion where the audience would be able to engage in a discussion with the speakers.

Mr Nicolas Jondet introduced the first speaker of the day, Professor Burkhard Schafer, whose talk was entitled "Johnny 5 Needs Input - Legal Tech, Digital Publishing and the Future of Law" and proposed that the way we think about the law has progressively changed by the way we communicate the law. Professor Schafer began by using the example of how pencils changed note taking abilities of lawyers, which in turn translated to greater access to legal knowledge. However, this greater access to knowledge was met with increased barriers in the form of archaic and cryptic language, thereby making it harder for the lay person to understand the law and allowing for the legal profession to maintain the knowledge monopoly over legal knowledge. The talk then moved to illustrating how disruptive technology, this time AI in the form of information retrieval tools were once again challenging the knowledge monopoly of legal knowledge. It was then asked whether increased access to justice in the form of AI could in turn translate to the death of the legal profession. Schafer indicated that legal precedent is set through the creative use of abnormal thinking made by human lawyers i.e. "finding that one uncited case which would tip the balance in your favour". Hence, Schafer believes that it is unlikely that AI will destroy the legal profession, but the way in which lawyers are trained will have to change e.g. in the form of creative legal thinking. Finally, the talk closed by saying that holders of legal data like LexisNexis are those who will hold all power in the future and that open access journals will be the only form of access to justice in the future. 
Mr Thomas Broderick introduced Dr Andres Guadamuz whose talk was entitled “Do Androids Dream of Electric Copyright?”. Dr Guadamuz began by showing several different pieces of art and asking the crowd by a show of hands which ones they thought were created by a machine, a game he called "BOT or NOT". It turned out that all apart from the last photo shown were created by machines. Dr Guadamuz stated that this is not only true for artistic expressions in the form of illustrations but also exits in music, games, and poetry etc. Dr Guadamuz asked whether works created by machines would be regarded as new works, and if so, whether they would be protected by copyright and who would be regarded as the author of this "new work". Dr Guadamuz then discussed approaches in different jurisdictions from the UK to the US, Japan and Australia, demonstrating how different jurisdictions have dealt with the issue of ownership over machine created works.

The final speaker of the day, Ms Annie Sorbie was introduced by Dr Catriona McMillan. Annie took us on a journey as to how she developed her talk entitled Our Genomic Future: Genome-edited Babies and Beyond. She began by analysing the interrelations between medicine, law, society and technology, noting the fact that she could have chosen any number of topics, but chose genome edited babies since it was topical and seemed to match the historical development of SCRIPTed as well. This was illustrated using a graph demonstrating that scientific experiments relating to genome editing began around the same time that SCRIPTed was established and that only recently, the first genome edited baby was born. Ms Annie Sorbie demonstrated that there was a lot of uncertainty around legal and ethical issues surrounding the birth of the first genome edited baby and how this would affect future generations. The talk concluded by saying that a lot more ethical and legal work would have to be carried out in the field of genome editing. 
The round table discussion was chaired by Dr Jiahong Chen who opened the discussion by analysing the overarching themes of the day. Dr Chen opened by saying that an overarching theme of the day was how technology has facilitated greater access to justice and how AI has acted as the platform for greater access, openness and transparency. The discussion then turned to how AI has been used to take advantage of the current legal system i.e. automated patent filing specifically in the field of biotech and automated copyright notices have disrupted the way in which intellectual property frameworks function. 